\title{
Percepção de Suporte Organizacional: Desenvolvimento e Validação de um Questionário
}

\author{
Gardênia Abbad de Oliveira-Castro \\ Ronaldo Pilati \\ Jairo Eduardo Borges-Andrade
}

\section{Resumo}

A literatura especializada em comportamento organizacional tem considerado o conceito de suporte organizacional muito importante na compreensão do desempenho no trabalho, do comprometimento, da cidadania e da rotatividade, mas as pesquisas nessa área carecem de medidas confiáveis de percepção de suporte. Este trabalho relata a experiência de construção de um questionário brasileiro de suporte, baseada na proposta teórica de Eisenberger et al. (1986) e em aspectos levantados numa amostra de trabalhadores de empresas privadas e órgãos públicos. Os itens, após análise qualitativa e validação semântica, foram transformados em questionário aplicado em uma amostra de 1384 trabalhadores. As respostas a esse questionário, submetidas a análises fatoriais (PAF) com rotação oblíqua, produziram dois tipos de estruturas empíricas: uma unifatorial - percepção de suporte organizacional, e outra com quatro subescalas - gestão de desempenho, carga de trabalho, suporte material ao desempenho e ascensão, promoção e salários. Todas têm altos índices de confiabilidade (alfas de Cronbach). São discutidas as aplicações desse questionário nas pesquisas sobre comportamento organizacional e sugeridos mais estudos que garantam maior generalidade aos resultados.

Palavras-chaves: suporte organizacional; gestão de desempenho; carga de trabalho; suporte material ao desempenho; ascensão, promoção e salários.

\begin{abstract}
The organizational behavior specialized literature has been considering the importance of the organizational support concept for the understanding of performance at work and of commitment, citizenship and turnover. However the research in the area needs reliable measures of the perception of support. This work reports the experience in developing a Brazilian questionnaire for support, based on Eisenberger et al. (1986) theoretical proposal and on private and public organizations workers surveyed aspects. These aspects were qualitatively analyzed and semantically validated and the resulting items were transformed in a questionnaire, that have been responded by a sample of 1384 workers. Their responses were submitted to a factorial analysis (PAF), with oblique rotation, and produced two types of empirical structures: one unifactorial - perception of organizational support and another with four sub-scales - performance management, work load, material support to performance and ascension, promotion and salaries. They all have high reliability scores (Cronbach's alphas). The use of this questionnaire in organizational behavior research is here discussed and more studies are suggested; they may insure a broader generalized utilization.
\end{abstract}

Key words: organizational support; performance management; work load; material support to performance; ascension, promotion and salaries. 


\section{INTRODUÇÃO}

Este trabalho ${ }^{(1)}$ relata a experiência de construção e validação de um instrumento de percepção de suporte organizacional, baseada na abordagem teórica proposta por Eisenberger et al. (1986). Trata-se de pesquisa de campo desenvolvida com o intuito de identificar indicadores objetivos de ações organizacionais de suporte organizacional, os quais, sob a forma de um questionário, foram submetidos a procedimentos de validação semântica, conceitual e empírica.

A literatura especializada vem mostrando que existem correlações positivas entre percepções favoráveis de suporte organizacional e medidas de desempenho no trabalho, comportamentos de cidadania organizacional, criatividade e inovação, o que torna as medidas dessa natureza muito promissoras como variáveis prognosticadoras das mais importantes variáveis, como critério da área de microcomportamento organizacional.

Apesar da importância de tais medidas, escalas de suporte organizacional ainda são pouco difundidas no Brasil. O trabalho de Siqueira (1995) pode ser citado como honrosa exceção. Em seu estudo sobre comportamentos de cidadania organizacional, Siqueira (1995) validou uma escala reduzida de percepção de suporte organizacional, adaptando o instrumento de Eisenberger et al. (1986) às características culturais brasileiras numa amostra de 287 trabalhadores.

Embora sem medida psicometricamente válida, como a desenvolvida por Siqueira (1995), as pesquisas brasileiras referentes a comprometimento organizacional feitas por Dias (1993), Borges-Andrade (1994a, 1994b), Bastos (1994) e Dias e Moraes (1994), já vinham indicando que variáveis organizacionais de suporte eram mais fortes prognósticos de comprometimento do que aquelas relativas à natureza das tarefas ou às características pessoais das amostras estudadas.

Tais diferenças seriam mais bem avaliadas, caso houvesse um instrumento específico de suporte organizacional que possibilitasse a padronização da coleta de dados acerca do referido construto, que permitisse exame mais sistemático dos relacionamentos entre as referidas variáveis.

Outras áreas de pesquisa também careciam de medidas de suporte organizacional, principalmente as que estavam preocupadas em estudar o impacto exercido por variáveis do nível organizacional sobre o desempenho no trabalho. As pesquisas em transferência de treinamento também necessitavam de instrumentos capazes de medir, de forma sistemática, as variáveis 
organizacionais responsáveis pela aplicação no trabalho de conhecimentos adquiridos em treinamentos.

Mowday e Sutton (1993) defenderam a idéia de investigar a influência distal exercida pelo suporte organizacional sobre desempenho e comprometimento organizacional e, ao mesmo tempo, analisar o efeito proximal de variáveis relativas a clima social no trabalho e suporte gerencial ao desempenho. $\mathrm{O}$ instrumento que busca medir variáveis que afetam distalmente o desempenho e o comprometimento do trabalhador com a organização é o Survey of Perceived Organizational Support (SPOS), desenvolvido por Eisenberger et al. (1986), com base em abordagem teórica que integra conceitos como norma de reciprocidade, ideologia da troca e modelo motivacional de esforço-resultado. O instrumento SPOS serve, segundo Eisenberger et al. (1986), para medir as avaliações feitas pelo trabalhador a respeito do valor das retribuições e benefícios dados pela organização em troca do seu esforço no trabalho.

Segundo Eisenberger et al. (1986), suporte organizacional refere-se às percepções do trabalhador acerca da qualidade do tratamento que recebe da organização em retribuição ao esforço que despende no trabalho. Essas percepções baseiam-se na freqüência, intensidade e sinceridade das manifestações organizacionais de aprovação, elogio, retribuição material e social ao esforço dos seus recursos humanos. Uma percepção favorável de suporte organizacional, segundo essa perspectiva, fortaleceria a expectativa esforço-resultado e o envolvimento afetivo do empregado com a organização, resultando em maior esforço do empregado para atingir os objetivos organizacionais.

O instrumento Survey of Perceived Organizational Support, tal como desenvolvem Eisenberger et al. (1986), é constituído por 36 itens em sua forma completa, e 17 itens, em sua forma reduzida. A forma completa inclui 23 categorias de conteúdo, discutidas mais adiante. Os itens estão associados a uma escala de concordância com 7 pontos, onde $1=$ Discordo Totalmente e $7=$ Concordo Totalmente. Metade dos itens tem conteúdo desfavorável e a outra metade favoráveis. O instrumento brasileiro desenvolvido por Siqueira (1995) constitui forma reduzida do SPOS e contém apenas itens de conteúdo favorável.

O SPOS e a forma reduzida de Siqueira (1995) foram construídos com base no pressuposto de que o trabalhador costuma desenvolver crenças globais a respeito do tipo de tratamento que recebe da organização onde trabalha. Segundo Eisenberger et al. (1986), tais percepções seriam comparáveis a avaliações antropomorfizadas de traços disposicionais da organização.

Ainda de acordo com essa proposta teórica, o trabalhador somente desenvolveria percepções favoráveis acerca do suporte organizacional, quando considerasse 
sinceras, bem intencionadas e não manipulativas as ações organizacionais de retribuição pelo esforço que despende no trabalho.

De acordo com Eisenberger et al. (1986), as interações do trabalhador com a organização se caracterizam por relações de troca marcadas por expectativas de reciprocidade. Segundo Gouldner (1960), a reciprocidade é norma social, apesar de não ocorrer em todos os casos de interações sociais. Reciprocidade, nesse contexto, é definida como padrão de trocas mutuamente dependentes entre duas unidades sociais. A abordagem funcionalista do sociólogo Gouldner (1960) sugere que uma unidade social se torna mais bem disposta a prestar auxílio a outra unidade, quando a última se mostra capaz de retribuir-lhe o benefício.

A interação entre o trabalhador e a organização não parece diferente. Há expectativas de reciprocidade nas interações entre indivíduo e organização. A organização, por um lado, tem obrigações legais, morais e financeiras com o seu membro e o direito de esperar que ele apresente bom desempenho, comprometimento e lealdade. $\mathrm{O}$ trabalhador, por sua vez, tem obrigação de apresentar bom desempenho e o dever de ser leal e comprometido com a organização. O contrato psicológico do trabalhador com a organização estabelece tais expectativas de trocas e benefícios mútuos.

O Survey of Perceived Organizational Support de Eisenberger et al. (1986) foi desenvolvido para medir as crenças do trabalhador sobre o tratamento que recebe da organização em retribuição aos seus esforços no trabalho. Este questionário tem sido submetido a um cuidadoso processo de validação conceitual. Muitas pesquisas vêm propiciando confirmação empírica da maior parte das proposições teóricas que embasaram a sua construção, como as realizadas por Eisenberger, Fasolo e LaMastro (1990), Shore e Tetrick (1991) e Siqueira (1995); no entanto os resultados desses estudos, apesar de encorajadores, ainda não são conclusivos a respeito da validade do SPOS e das suas formas reduzidas.

Visando à construção de instrumento de medida adaptado às necessidades da pesquisa nacional, desenvolveu-se o questionário Percepção de Suporte Organizacional com base em pesquisa de campo e numa revisão da literatura sobre o tema. A seguir, descreve-se a metodologia empregada na construção e validação deste questionário.

\section{Método de Desenvolvimento e Validação do Questionário}

O questionário Percepção de Suporte Organizacional foi desenvolvido e vali- 
dado de acordo com as seguintes etapas: (1) escolha da técnica de coleta de dados; (2) levantamento e sistematização dos indicadores de suporte organizacional; (3) validação teórica do conteúdo; (4) validação semântica; e (5) validação empírica do conteúdo do questionário.

Na primeira etapa, escolha da técnica de coleta de dados, foram testados 2 procedimentos de coleta em amostra de 15 trabalhadores lotados em uma organização do Serviço Público Federal e em uma empresa privada sedeadas em Brasília, DF. Em um dos procedimentos, solicitava-se ao participante que listasse 5 incidentes, em total de 15, que ilustrassem os 3 tipos de disposições ou ações organizacionais demonstrativas de (1) empenho em valorizar o funcionário e cuidar do seu bem-estar; (2) indiferença em relação ao trabalhador; e (3) desvalorização do trabalhador e nenhum cuidado com o seu bem-estar.

No segundo procedimento, solicitava-se ao participante que descrevesse 15 situações características de uma organização bem sucedida em manter os seus trabalhadores: (1) comprometidos, motivados, produtivos, pontuais e com intenção de permanecer na organização; (2) indiferentes e acomodados; e (3) descomprometidos, desmotivados, insatisfeitos, pouco produtivos, freqüentemente ausentes do trabalho e com intenção de sair da organização. Cada sujeito deveria descrever 5 incidentes ilustrativos de cada uma dessas 3 situações. Metade da amostra respondeu ao questionário na seqüência 1 (primeiro procedimento seguido do segundo), e a outra metade, na seqüência inversa. A aplicação do instrumento foi coletiva.

Os dados assim coletados foram submetidos a uma análise qualitativa, selecionando-se o procedimento mais eficaz, conforme os seguintes critérios: (1) riqueza e diversidade das descrições obtidas; (2) compatibilidade conceitual dos incidentes e com as dimensões subjacentes ao construto percepção de suporte organizacional; (3) compatibilidade dos itens com as medidas das características organizacionais utilizadas em pesquisas brasileiras sobre comprometimento organizacional.

As comparações resultantes dessas análises mostraram que as duas formas de solicitar exemplos de ações representativas de suporte organizacional produziam respostas qualitativamente similares, de acordo com os 3 primeiros critérios. Não foram encontrados efeitos da seqüência de apresentação dos itens. Observou-se apenas uma diminuição do número de respostas, no segundo procedimento da seqüência, provavelmente devido à fadiga gerada pelo número excessivo de incidentes requeridos.

O primeiro procedimento, com algumas modificações, foi considerado o mais claro e o mais fácil de aplicar. A coleta de dados deixou de ser realizada por meio 
do questionário de perguntas abertas e passou a envolver entrevistas individuais semi-estruturadas com menor número de itens pesquisados (10 incidentes e não 15) e instruções mais simples. Sete alunos de graduação do curso de psicologia da Universidade de Brasília foram treinados na aplicação das entrevistas, que duraram, em média, 40 minutos.

A etapa 2, levantamento e sistematização dos indicadores de suporte organizacional, compreendeu a aplicação da referida entrevista em amostra de 113 trabalhadores de organizações públicas e de economia mista, além de trabahadores de empresas privadas sedeadas em Brasília. Como resultado desse levantamento, foram obtidos 1292 indicadores de percepção de suporte organizacional, os quais foram submetidos, posteriormente, à análise qualitativa, que compreendeu a identificação das dimensões ou categorias de conteúdo subjacentes a essas afirmativas. Na terceira etapa, os itens classificados de acordo com 8 categorias de conteúdo foram semanticamente comparados às categorias do SPOS e às de outros instrumentos de medida correlatos.

Os indicadores coletados a partir da amostra nacional foram comparados aos itens do SPOS e aos itens componentes de instrumentos supostamente similares à percepção de suporte, como clima, cultura, qualidade de vida, satisfação geral e específica no trabalho. Em decorrência dessas avaliações de conteúdo, foram excluídos todos os indicadores coletados junto à amostra, que não guardavam similaridade de conteúdo com os itens do Survey of Perceived Organizational Support ou que apresentavam conteúdo equivalente aos de outros instrumentos estudados.

A partir dessas análises, foi possível identificar e selecionar os itens componentes da primeira versão do questionário Percepção de Suporte Organizacional, que foi submetida, na quarta etapa, a procedimentos de validação semântica. $\mathrm{Na}$ quinta etapa, o questionário com 58 itens, associados a uma escala Likert de concordância, foi aplicado em amostra de 1384 trabalhadores de 53 organizações públicas e privadas sediadas em Brasília (DF), Uberlândia (MG) e Salvador (BA). As respostas dessa amostra foram submetidas a análises descritivas e fatoriais (PAF) com rotação oblíqua e cálculos de confiabilidade (alfa de Cronbach). Os resultados desse trabalho estão descritos a seguir.

\section{Resultados e Discussão}

Os resultados são apresentados na seqüência que segue: (1) categorias de conteúdo e indicadores de suporte; (2) validade teórica dos indicadores de percepção 
de suporte organizacional; (3) validade semântica do questionário; e (4) validade do conteúdo empírico do questionário.

\section{Categorias de Conteúdo e Indicadores de Suporte}

De modo geral, os indicadores de percepção de suporte organizacional coletados na amostra de 113 trabalhadores brasilienses mostraram-se muito ricos, muito mais claros e objetivos que os itens do SPOS. A concepção de suporte organizacional dos trabalhadores apresenta distinções e avaliações mais sutis e refinadas dos aspectos do comportamento da organização que cumpre levar em conta em modelo teórico sobre o assunto.

Foram entrevistados 31 trabalhadores de organizações públicas, 22 de empresas estatais e 60 de 10 empresas privadas. Os componentes da amostra tinham escolaridade igual ou superior ao segundo grau completo e um ano ou mais de tempo de serviço na organização onde trabalhavam, na época da coleta de dados.

A análise de conteúdo dos 1292 indicadores de suporte organizacional revelou que os itens podiam ser classificados segundo 8 categorias de conteúdo, assim definidas: (1) benefícios e saúde: referem-se às ações organizacionais que propiciam salários indiretos e possibilitam acesso a serviços de assistência médica; (2) conforto, condições de trabalho e bem-estar: referem-se ao gerenciamento da jornada de trabalho e das condições físicas e materiais dos ambientes de trabalho; (3) desenvolvimento e carreira: referem-se às ações organizacionais que indicam preocupação organizacional com o futuro profissional e pessoal dos funcionários; (4) incentivos, remuneração e gestão de desempenho: referem-se às estratégias empregadas pela organização para manter e melhorar os níveis de desempenho dos seus funcionários e à qualidade das políticas e práticas organizacionais relativas à administração de salários; (5) justiça: refere-se à qualidade dos procedimentos e critérios de distribuição de benefícios e recompensas organizacionais; (6) treinamento: refere-se às oportunidades de capacitação profissional oferecidas pela organização aos seus funcionários, com a finalidade de corrigir e aprimorar as suas competências; (7) relacionamento, comunicação e participação: referem-se à qualidade do relacionamento interpessoal na organização; (8) outras características do comportamento organizacional: incluem afirmações que não foram classificadas nas categorias anteriormente mencionadas.

Analisou-se a freqüência de categorias de indicadores por organização. Observou-se, por exemplo, que havia poucas diferenças entre as respostas das amostras de trabalhadores de organizações públicas e privadas. A diferença mais saliente, no entanto, ocorreu na categoria benefícios e saúde do trabalhador, em que a 
amostra das empresas privadas produziu número muito maior de incidentes do que a das organizações públicas.

\section{Validade Teórica dos Indicadores de Percepção de Suporte Organizacional}

As categorias de indicadores de suporte, após a eliminação de redundâncias, foram comparadas às 23 dimensões relevantes do SPOS de Eisenberger et al. (1986). Com base nessas avaliações, selecionaram-se os itens mais representativos das dimensões de suporte, mantendo-se também os que não apresentavam conteúdo equivalente aos itens de outros instrumentos de medidas correlatas.

Inicialmente, foram realizadas comparações entre as categorias de percepção de suporte organizacional do SPOS de Eisenberg et al. (1986) e as de instrumentos de clima social do trabalho (Puente e Günther, 1997), clima organizacional (Sbraglia, 1983; Souza 1983), cultura organizacional (Xavier, 1987) e qualidade de vida no trabalho (Quirino e Xavier, 1987; Dias, 1993). No Quadro 1, apresenta-se um sumário dessas análises.

\section{Quadro 1: Comparações entre Instrumentos de Percepção de Suporte Organizacional, Clima, Cultura e Qualidade de Vida no Trabalho}

\begin{tabular}{|c|c|c|c|c|}
\hline Percepção de Suporte Organizacional (SPOS) & Clima Social & $\begin{array}{c}\text { Clima } \\
\text { Organizacional }\end{array}$ & Cultura & QVT \\
\hline 1.Satisfação com o empregado como membro. & não & não & não & não/não \\
\hline 2. Antecipação do futuro valor do empregado. & não & não & não & não/não \\
\hline 3. Apreciação do esforço extra. & não & não & não & não/não \\
\hline 4. Consideração pelos objetivos/opiniões. & não & não & não & não/não \\
\hline 5. Pleno uso dos talentos do empregado. & não & não & não & não/não \\
\hline 6. Preocupação com a satisfação do empregado no trabalho. & não & não & não & não/não \\
\hline 7. Preocupação com o bem-estar do empregado. & não & não & não & não/não \\
\hline 8. Prontidão para ajudar o empregado com problema. & não & não & não & não/não \\
\hline 9. Substituição por outro com menor salário. & não & não & não & não/não \\
\hline 10. Respostas às queixas. & não & não & não & não/não \\
\hline 11. Prontidão para prestar favor especial. & não & não & não & não/não \\
\hline 12. Respostas à decisão de deixar a organização. & não & não & não & não/não \\
\hline 13. Resposta ao não cumprimento de prazos. & não & não & não & não/não \\
\hline 14. Manutenção do empregado quando o trabalho fica obsoleto. & não & não & não & não/não \\
\hline 15. Recontratação depois de demissão. & não & não & não & não/não \\
\hline 16. Satisfação com o desempenho do empregado. & $\operatorname{sim}$ & $\operatorname{sim}$ & $\operatorname{sim}$ & $\operatorname{sim} / \operatorname{sim}$ \\
\hline 17. Preocupação com o salário justo. & não & $\operatorname{sim}$ & não & não/sim \\
\hline 18. Respostas aos erros. & não & $\operatorname{sim}$ & não & não/não \\
\hline 19. Respostas à diminuição no nível de desempenho. & não & $\operatorname{sim}$ & não & não/não \\
\hline 20. Respostas a melhorias no desempenho. & $\operatorname{sim}$ & $\operatorname{sim}$ & não & $\operatorname{sim} / \operatorname{sim}$ \\
\hline 21. Respostas a pedidos de mudança no ambiente. & não & $\operatorname{sim}$ & não & não/não \\
\hline 22. Oportunidades de promoção. & não & $\operatorname{sim}$ & $\operatorname{sim}$ & $\mathrm{sim} / \mathrm{sim}$ \\
\hline 23. Enriquecimento do trabalho. & $\operatorname{sim}$ & não & não & não/sim \\
\hline
\end{tabular}

Legenda: $\operatorname{sim}$ - itens com conteúdo semelhante; não - itens com conteúdo diferente.

Essas comparações foram feitas com o intuito de aumentar a precisão da escala 
brasileira, eliminando-se dela os indicadores cujo conteúdo pertencesse a outras medidas. Observaram-se, por exemplo, semelhanças nos conteúdos dos diferentes instrumentos, no que diz respeito ao tipo de conseqüências atribuídas ao desempenho do funcionário (ver categorias 16, 18, 19 e 20 no Quadro 1), às respostas organizacionais a queixas do funcionário (ver categoria 10 ) e às oportunidades de promoção (ver categoria 22).

O questionário de clima social no local de trabalho de Puente e Günther (1997), de forma geral, não se refere à percepção dos indivíduos sobre os aspectos globais do comportamento organizacional, como o que se quer medir por meio de questionário de percepção de suporte organizacional. Isso se manifesta pelo tipo de agentes ou sujeitos das ações descritas nos itens. No questionário de clima, os agentes são pessoas, chefes, funcionários, enquanto naquele de suporte o agente principal é a organização como um todo. Além disso, os instrumentos diferem entre si quanto ao tipo de resposta requerida do participante. No instrumento de clima social, as respostas são do tipo dicotômico, sim/não, enquanto no SPOS são do tipo Likert de 7 pontos de concordância.

O instrumento de qualidade de vida no trabalho empregado por Dias (1993) e o SPOS se referem às oportunidades de promoção, mas não abordam aspectos como freqüência e magnitude de tal tipo de ação organizacional, fundamentais na abordagem de percepção de suporte de Eisenberger et al. (1986). O mesmo pode ser dito em relação aos instrumentos de cultura (Xavier,1986), qualidade de vida no trabalho de Quirino e Xavier (1987) e os de clima organizacional de Sbraglia (1983), Souza (1983) e Xavier (1986), como pode ser observado na Quadro 1.

Em que pesem as aparentes sobreposições de conteúdo, o questionário Percepção de Suporte Organizacional apresentado no presente trabalho, para manter coerência com a abordagem teórica de Eisenberger et al. (1986), que lhe deu origem, contém indicadores específicos de ações de suporte relativos a pagamento, oportunidades de promoção e ascensão.

A análise dos dados da amostra brasiliense revelou que os trabalhadores apresentavam concepção de suporte organizacional ao bem-estar do funcionário muito mais detalhada e rica do que a empregada por Eisenberger et al. (1986) na concepção dos itens do SPOS.

Para Eisenberger et al. (1986), por exemplo, demonstrações de preocupação organizacional com o bem-estar do empregado referem-se à consideração pelos interesses e objetivos do empregado, oferecimento de ajuda técnica e pessoal, tratamento humano e preocupação em não explorar o funcionário, ao passo que, para a amostra brasiliense, a preocupação organizacional com o bem-estar do 
funcionário inclui, além desses aspectos, outros como: preocupação com o conforto físico dos ambientes de trabalho, o lazer e a integração social dos funcionários, a segurança pessoal, a salubridade no trabalho, as condições e horários de trabalho, além de concessão de benefícios por meio de salários indiretos.

Os itens referentes a conforto físico e lazer foram excluídos da proposta de questionário aqui apresentada, já que eram mais típicos do instrumento de clima social no trabalho (9 itens) de Puente e Günther (1997), além de constarem do instrumento de QVT de Quirino e Xavier (1987) (1 item) e de não apresentarem correspondência com os itens do SPOS.

As afirmativas referentes a lazer, encontradas nos indicadores de suporte da amostra brasiliense, foram excluídas do instrumento, por não integrarem o conceito de suporte organizacional e por parecerem mais compatíveis com indicadores de qualidade de vida no trabalho, apesar de não constarem do questionário de Dias (1993).

A abordagem teórica do SPOS não se refere explicitamente à preocupação com segurança (salubridade) no trabalho. $\mathrm{Na}$ amostra brasiliense, entretanto, foram encontrados indicadores com esse conteúdo. Alguns itens desse tipo foram mantidos na presente proposta de instrumento, por serem teoricamente compatíveis com o SPOS. É que se referiam à preocupação com o bem-estar do funcionário, em oposição ao interesse puramente calculista de organização, cujas práticas organizacionais valorizam apenas a produtividade, e não há preocupação em dispensar tratamento humano ao funcionário.

Nas pesquisas brasileiras sobre comprometimento organizacional, esse conteúdo aparece como segurança e salubridade, nos trabalhos de Borges-Andrade (1994a) e de Bastos (1994). Salubridade foi definida por Bastos (1994) como "medida em que as condições de trabalho são inseguras, geram demandas excessivas que podem afetar a saúde do trabalhador". Na amostra brasiliense, tal categoria de conteúdo foi identificada, porém não foi incluída na proposta de instrumento, por não corresponder às categorias de conteúdo do SPOS. Tais itens assemelham-se mais aos do instrumento denominado Safety Climate Questionnaire de Zohar (1980) - preocupação em dar treinamento em segurança no trabalho e com o nível de risco do local de trabalho.

Alguns indicadores de suporte relativos à flexibilidade e rigidez no controle dos horários de trabalho, apesar de não estarem explicitamente colocados no SPOS, foram incluídos no instrumento brasiliense como exemplos de ações organizacionais que demonstram: (1) prontidão para ajudar o empregado com problemas pessoais; (2) preocupação com o bem-estar do funcionário e; (3) prontidão para fazer algum favor especial ao empregado, as quais estão contidas no SPOS. 
O instrumento de percepção de suporte organizacional não contém a preocupação da organização em conceder benefícios e salários indiretos, qualidade do relacionamento interpessoal, comunicação organizacional e tomada de decisão. Os primeiros foram excluídos por não serem compatíveis com a abordagem teórica do SPOS. Os três últimos foram considerados pertencentes a abordagens de clima social no trabalho e a estilos organizacionais.

Itens referentes à abertura da organização às idéias e sugestões dos funcionários, quanto à resolução de problemas de trabalho, compatíveis com a abordagem do SPOS, foram todos mantidos nesta proposta de instrumento.

Os indicadores de oportunidades de treinamento não apareceram no SPOS de Eisenberger et al. (1986), mas, de acordo com a abordagem motivacional proposta, tais oportunidades teriam valor instrumental, melhorando as expectativas de o funcionário obter sucesso no trabalho e aumentando as chances de o trabalhador obter as recompensas desejadas.

Segundo esse ponto de vista, percepções favoráveis sobre esse aspecto podem resultar em avaliações positivas do funcionário em relação à organização. Tal relacionamento guarda, pois, semelhanças teóricas com as categorias enriquecimento do trabalho e promoções, presentes no SPOS. Por esse motivo e pelo fato de que oportunidades de treinamento vêm sendo descobertas como fortes prognósticos de comprometimento organizacional, nas pesquisas brasileiras (e.g.: Bastos, 1994; Dias e Moraes, 1994), mantiveram-se os itens relativos a oportunidades de treinamento no questionário deste trabalho.

Além dessas avaliações de conteúdo, foram feitas outras, comparando-se as categorias de conteúdo do questionário de percepção de suporte com 19 descrições de instrumentos de satisfação geral e específica, constantes do compêndio de medidas e ditado por Cook et al. (1981).

$\mathrm{Na}$ presente pesquisa, foram identificadas similaridades entre os itens de percepção de suporte e os de algumas escalas de satisfação geral, citadas por Cook et al. (1981), no que concerne à satisfação do trabalhador com pagamento no Minnesota Satisfaction Questionnaire e no Overall Job Satisfactions. Este último instrumento também contém itens referentes à satisfação com o reconhecimento pelo bom trabalho, oportunidade de usar habilidades e atenção às sugestões do empregado, semelhantes a categorias do SPOS.

Curiosamente observou-se que a satisfação do empregado com a organização vem sendo tratada como item componente de instrumentos de satisfação específica no trabalho, em diversas escalas descritas por Cook et al. (1981). Apesar de pertencerem a um nível de análise mais abrangente, as atitudes do empregado em 
relação à organização vêm sendo colocadas erroneamente no mesmo nível da satisfação com supervisores, pares e tarefas.

Observou-se, também, que há semelhança entre os itens das escalas Job Descriptive Index, Managerial Opinion Survey, Worker Opinion Survey, Specific Satisfactions, Facet Specific Job Satisfaction, citadas por Cook et al. (1981), e o questionário de percepção de suporte, no que se refere às categorias relacionadas a pagamento e oportunidades de promoção. O conteúdo pagamento aparece também no instrumento denominado Intrinsic and Extrinsic Rewards Satisfaction, citado no trabalho de Cook et al. (1981).

Apesar das semelhanças, foram encontradas algumas diferenças profundas entre os instrumentos de satisfação e o questionário Percepção de Suporte Organizacional. De acordo com Shore e Tetrick (1991), por exemplo, a percepção de suporte é medida global de comprometimento da organização com o seu funcionário, enquanto a satisfação focaliza vários aspectos específicos do trabalho, pertencentes a outros níveis de análise.

De modo geral, os instrumentos de satisfação são medidas do impacto de características do trabalho sobre as atitudes do trabalhador, que não se referem a características do comportamento organizacional ou ao grau com que essas características revelam comprometimento da organização com os funcionários. O instrumento Overall Job Satisfaction citado em Cook et al. (1981), por exemplo, mede a satisfação com a organização com item único, mas também não se refere às razões que levam o participante a dizer que está satisfeito com a organização como um todo.

Os itens referentes à satisfação com promoção, pagamento, oportunidades de ascensão, nos instrumentos de satisfação, são vagos demais, deixando de explicitar, por exemplo, a intensidade, a freqüência e a sinceridade das ações organizacionais a elas correspondentes, o que, para a abordagem de Eisenberger et al. (1986), na proposta que originou o presente trabalho, é importante e necessário.

De forma geral, também não há semelhanças entre o questionário Percepção de Suporte Organizacional e a escala Perceptions of Corporate Responsability de Gavin e Maynard (1975). Esta última refere-se a preocupações organizacionais com a pobreza mundial, consumismo, ecologia, direitos civis, assim como com o bem-estar físico e psicológico dos trabalhadores. Refere-se, pois, à obrigação ética da organização de avaliar os efeitos das suas decisões e ações sobre o sistema social como um todo.

Em uma de suas subescalas, no entanto, há 12 itens, em que os participantes devem avaliar o quanto acreditam que certas recompensas relacionadas ao traba- 
lho (aumento de salário, promoção e segurança no trabalho) são dependentes ao desempenho eficaz. Esse questionário foi construído com base no modelo motivacional de expectativa e, nesse ponto, assemelha-se à abordagem teórica subjacente à construção do SPOS e do questionário brasileiro. Na referida subescala, há questões como: de que forma apresentar um desempenho exemplar afeta as suas (do trabalhador) chances de promoção? Esse tipo de pergunta apresenta semelhanças com os indicadores de suporte organizacional coletados na amostra brasileira, os quais foram mantidos no questionário Percepção de Suporte Organizacional, por se mostrarem muito compatíveis com a abordagem de trocas e expectativas de reciprocidade subjacentes ao SPOS.

Alguns itens do questionário Percepção de Suporte Organizacional têm a função de medir o grau de confiança depositado pelo trabalhador nas ações organizacionais de elogio, recompensa e incentivo. Essas afirmativas não mantêm correspondência direta com os itens do SPOS, porém são compatíveis com a proposta teórica de Eisenberger et al. (1986) e, por esse motivo, foram mantidas na primeira versão do questionário de suporte organizacional.

O alvo das ações organizacionais focalizadas nas afirmativas deste questionário é o trabalhador, de modo geral, e não o participante, de modo especial. Tal formulação de itens visa a evitar que o instrumento passe a ser medida da história pessoal do empregado em relação às práticas organizacionais. O que se quer obter é uma medida das percepções do trabalhador a respeito do comportamento predominante da organização em relação ao seu corpo de funcionários. Neste ponto, o questionário aqui apresentado também difere do proposto por Eisenberger et al. (1986). No SPOS, o alvo das ações é o próprio respondente do questionário como no item a organização cuida do meu bem-estar, enquanto no questionário brasileiro o alvo é o funcionário, como no item a organização procura melhorar constantemente as condições físicas de trabalho, de acordo com as solicitações dos funcionários.

Os itens de conteúdo desfavorável estão presentes em maior número que os favoráveis no questionário Percepção de Suporte Organizacional, tal como ocorreu nas respostas da amostra de dados utilizados na construção dos itens. Essa desproporção de itens favoráveis X desfavoráveis foi mantida por três motivos principais: (1) para garantir a clareza das afirmativas, visto que alguns indicadores foram mais bem descritos pela amostra brasiliense como exemplos negativos de falta de suporte organizacional; (2) para manter coerência com a abordagem teórica proposta por Peters e O'Connor (1982), segundo a qual as diferenças reais observadas no desempenho e nas respostas afetivas dos trabalhadores em relação aos seus ambientes de trabalho se devem, em grande parte, ao nível de restrições situacionais existentes na organização; (3) e, finalmente, para manter coerência 
com os achados da pesquisa realizada por Oliveira-Castro (1996), que levou a cabo um grande levantamento de indicadores de desempenho funcional, em que foram muito freqüentes os casos nos quais os trabalhadores tiveram mais facilidade e maior fluência na produção de exemplos de indicadores desfavoráveis do que favoráveis de desempenho.

Em suma, o SPOS de Eisenberger et al. (1986), o instrumento de Siqueira (1995) e o questionário Percepção de Suporte Organizacional são instrumentos conceitualmente distintos daqueles que medem clima, cultura, qualidade de vida no trabalho, satisfação e percepção de responsabilidade organizacional, no que se refere à maior parte de seus componentes.

O SPOS de Eisenberger et al. (1986) e a escala reduzida desenvolvida por Siqueira (1995) podem ser considerados instrumentos promissores, porém não totalmente adequados aos objetivos das pesquisas brasileiras sobre comprometimento organizacional, as quais necessitavam de instrumento capaz de especificar clara e objetivamente as ações ou práticas organizacionais que seriam julgadas pelo participante.

O SPOS contém afirmativas de conteúdo vago e genérico demais, dificultando a interpretação dos dados. É o caso, por exemplo, das afirmativas que dizem: a organização realmente cuida do meu bem-estar ou a organização mostra-se muito pouco preocupada comigo, cujo conteúdo não deixa claro o que significam cuidado com o bem-estar ou preocupação com o trabalhador. O problema com esse tipo de afirmativa é que ela não possibilita a formulação de conclusões precisas sobre as razões que levaram o respondente a considerar a organização suportiva ou não suportiva.

A identificação de indicadores mais objetivos de suporte organizacional, tal como a realizada neste trabalho, poderia, nesse contexto, aumentar a precisão e a validade das avaliações de suporte, sem contrariar as proposições teóricas de Eisenberger et al. (1986).

\section{Validade Semântica do Questionário}

Os 76 itens resultantes das análises anteriores foram submetidos à validação semântica, por meio da aplicação individual do questionário em amostra de 20 trabalhadores brasilienses com escolaridade igual ou superior ao segundo grau completo e através de uma avaliação por três especialistas, pesquisadores da área de psicologia organizacional. Como resultado de todas essas avaliações, obtevese a proposta de instrumento com 76 indicadores de suporte organizacional. As afirmativas componentes dessa minuta do questionário apresentavam exemplos 
de ações organizacionais favoráveis e desfavoráveis e estavam associadas a um escala de concordância de 5 pontos, onde 1 corresponde a discordo totalmente e 5 a concordo totalmente. Em decorrência do processo de validação semântica, foram aprimoradas as instruções e eliminados alguns itens. O questionário assim construído passou a conter 52 afirmativas.

\section{Validade Empírica do Conteúdo do Questionário}

Nesta última etapa, de testagem empírica, o instrumento foi aplicado na amostra de 1384 trabalhadores em duas oportunidades: a primeira realizada no ano de 1996, e a segunda no ano seguinte. Os participantes eram provenientes de 53 organizações públicas e privadas sedeadas em Brasília (DF), Uberlândia (MG) e Salvador (BA).

As respostas dos 1384 participantes aos itens do questionário, submetidas a análises descritivas, produziram médias que variaram entre 1,83 e 3,67 e desvios padrões de 1,24 e 1,57. Foram poucos os casos de respostas em branco registrados nas análises. Essas respostas da amostra foram submetidas a análises fatoriais do tipo PAF com rotação oblimin e tratamento listwise para os dados omissos. Essas análises foram realizadas por meio do pacote estatístico SPSS, versão 7,5 para Windows.

A inspeção dos valores do determinante da matriz e do KMO mostraram que a matriz de dados era fatorável e que havia fortes indícios de que o construto percepção de suporte organizacional tinha estrutura unidimensional. Por esse motivo, inicialmente, resolveu-se forçar a solução em apenas um fator. Foram excluídos desse fator único os itens cujas cargas fatoriais não atingiram valores iguais ou superiores a 0,30 .

A Tabela 1 apresenta as cargas fatoriais e as comunalidades associadas aos 50 itens do fator único, denominado percepção de suporte organizacional. Esse fator geral apresentou elevado índice de consistência interna $(\alpha=0,95)$ e explicação de $28 \%$ da variância das respostas da amostra aos itens. Observa-se, nesta tabela, que apenas dois itens, o S7 e o S24, foram excluídos do fator, por apresentarem cargas fatoriais inferiores a 0,30 . O primeiro item dizia que a organização obriga o funcionário a cumprir horas extras, e o último que, na organização, se costuma chamar a atenção do funcionário por pequenas falhas e erros cometidos no trabalho. 


\section{Tabela 1: Percepção de Suporte Organizacional como Fator Único}

\begin{tabular}{|c|c|c|c|}
\hline Item & Conteúdo básico dos itens do questionário & $\begin{array}{c}\text { Carga } \\
\text { Fatorial }\end{array}$ & $\mathbf{h}^{2}$ \\
\hline S51 & Toma providências para sanar dificuldades ao desempenho eficaz. & 0,654 & 0,428 \\
\hline S19 & Cumpre promessas. & 0,652 & 0,426 \\
\hline S15 & Dinamiza e moderniza processos de trabalho. & 0,633 & 0,401 \\
\hline S28 & Fornece os equipamentos necessários ao desempenho eficaz. & 0,619 & 0,383 \\
\hline S35 & Adquire lentamente os equipamentos de segurança no trabalho. & $-0,618$ & 0,382 \\
\hline S23 & Atualiza o funcionário quanto às novas tecnologias. & 0,617 & 0,381 \\
\hline $\mathrm{S} 12$ & Melhora constantemente as condições físicas do local de trabalho. & 0,614 & 0,376 \\
\hline S43 & Interessa-se apenas pela produção. & $-0,610$ & 0,372 \\
\hline S06 & Valoriza novas idéias. & 0,608 & 0,370 \\
\hline S52 & Procura adquirir equipamentos modernos de trabalho. & 0,607 & 0,369 \\
\hline S26 & Fornece informações necessárias à execução eficaz das tarefas. & 0,604 & 0,365 \\
\hline S20 & Procura conhecer dificuldades na execução das tarefas. & 0,601 & 0,361 \\
\hline S46 & Promoção e ascensão compatíveis com aspirações pessoais. & 0,586 & 0,343 \\
\hline S07 & Leva em conta o esforço do funcionário para atingir resultados. & 0,584 & 0,341 \\
\hline S05 & Fornece materiais em quantidade suficiente. & 0,583 & 0,340 \\
\hline S21 & Salários que reduzem o impacto da inflação. & 0,582 & 0,339 \\
\hline S47 & Investe na capacitação profissional do funcionário. & 0,575 & 0,331 \\
\hline S31 & Mantém coerência entre diretrizes, metas e ações. & 0,558 & 0,312 \\
\hline S38 & Coloca funcionários em locais incompatíveis com suas características pessoais. & $-0,556$ & 0,309 \\
\hline S27 & Efetua constantemente a manutenção de máquinas e equipamentos. & 0,548 & 0,300 \\
\hline S41 & Presta orientação técnica ao funcionário. & 0,538 & 0,289 \\
\hline S40 & Consulta o funcionário antes de promover mudanças no trabalho. & 0,536 & 0,287 \\
\hline S29 & Desvaloriza os esforços do funcionário. & $-0,535$ & 0,286 \\
\hline S39 & Libera recursos financeiros em tempo hábil. & 0,530 & 0,281 \\
\hline S08 & Funcionário exemplar recebe mais recompensas que os outros. & 0,530 & 0,280 \\
\hline S32 & Mantém inadequados os ambientes de trabalho. & $-0,527$ & 0,278 \\
\hline S50 & Determina prazos irreais para a entrega de trabalhos. & $-0,522$ & 0,273 \\
\hline S11 & Final de carreira com salários baixos. & $-0,485$ & 0,236 \\
\hline S30 & Fornece ferramentas de má qualidade. & $-0,484$ & 0,235 \\
\hline S22 & Oferece suporte financeiro extra. & 0,475 & 0,225 \\
\hline S09 & Propicia salários compatíveis com os melhores do mercado. & 0,466 & 0,217 \\
\hline S36 & Não oferece cargos importantes para o funcionário. & $-0,465$ & 0,216 \\
\hline S02 & Pouco reconhecimento pelo trabalho bem feito. & $-0,465$ & 0,216 \\
\hline S01 & Deixa faltar os materiais necessários ao bom desempenho. & $-0,464$ & 0,215 \\
\hline S18 & Desenvolve as capacidades do funcionário. & 0,460 & 0,212 \\
\hline S25 & Promove o funcionário para cargos melhor remunerados. & 0,457 & 0,209 \\
\hline S17 & Oferece raras oportunidades de promoção. & $-0,452$ & 0,204 \\
\hline S16 & Prefere contratar pessoal externo, a treinar o pessoal interno. & $-0,447$ & 0,200 \\
\hline S34 & Sobrecarrega de trabalho os melhores funcionários. & $-0,444$ & 0,197 \\
\hline S42 & Mantém sujos os locais de trabalho. & $-0,440$ & 0,193 \\
\hline S48 & Mantém baixas as recompensas financeiras. & $-0,431$ & 0,185 \\
\hline S03 & Paga salário digno ao funcionário. & 0,428 & 0,183 \\
\hline S04 & Funcionário conhece metas de desempenho esperadas. & 0,421 & 0,177 \\
\hline S49 & Funcionário opina decisivamente na resolução de problemas. & 0,419 & 0,176 \\
\hline S13 & Presta orientação pessoal ao funcionário. & 0,418 & 0,175 \\
\hline S44 & Não incentiva escolaridade excedente. & $-0,405$ & 0,164 \\
\hline S10 & Desconsidera sugestões de mudança nas rotinas de trabalho. & $-0,381$ & 0,145 \\
\hline S45 & Suga a energia do funcionário. & $-0,365$ & 0,133 \\
\hline S33 & Submete o funcionário a uma carga excessiva de trabalho. & $-0,349$ & 0,122 \\
\hline S14 & $\begin{array}{l}\text { Desconsidera interesses pessoais, ao tomar decisões administrativas que } \\
\text { envolvem o funcionário. }\end{array}$ & $-0,304$ & 0,092 \\
\hline
\end{tabular}

Depois dessa análise, realizou-se outra análise fatorial (PAF) com rotação oblíqua e tratamento listwise de casos omissos, forçada em 4 fatores, que resultou em 
4 subescalas de percepção de suporte organizacional com altos índices de confiabilidade. A primeira, denominada gestão de desempenho é apresentada na Tabela 2 , e se refere à opinião dos trabalhadores sobre as práticas organizacionais de gerenciamento do desempenho do funcionário: estabelecimento de metas, valorização de novas idéias, conhecimento de dificuldades na execução eficaz das tarefas práticas organizacionais de gerenciamento do desempenho dos funcionários, como estabelecimento de metas, valorização de novas idéias, conhecimento de dificuldades associadas à execução eficaz das tarefas e esforço organizacional de atualização de seus colaboradores ou empregados em face das novas tecnologias e processos de trabalho. Esse primeiro fator alcançou alto índice de consistência interna ( $\alpha$ de Cronbach) de 0,87 ; explica sozinho $28 \%$ da variância total das respostas da amostra ao questionário e contém 13 itens.

\section{Tabela 2: Primeiro Fator: Gestão de Desempenho}

\begin{tabular}{llcc}
\hline Item & \multicolumn{1}{c}{ Conteúdo básico dos itens } & $\begin{array}{c}\text { Carga } \\
\text { Fatorial }\end{array}$ & h2 \\
\hline S06 & Valoriza novas idéias. & 0,555 & 0,484 \\
S49 & Funcionário opina decisivamente na resolução de problemas. & 0,429 & 0,256 \\
S40 & Consulta o funcionário antes de promover mudanças no trabalho. & 0,419 & 0,415 \\
S07 & Leva em conta o esforço do funcionário para atingir resultados. & 0,413 & 0,345 \\
S20 & Procura conhecer dificuldades na execução das tarefas. & 0,392 & 0,396 \\
S26 & Fornece informações necessárias à execução eficaz das tarefas. & 0,374 & 0,397 \\
S31 & Mantém coerência entre diretrizes, metas e ações. & 0,355 & 0,436 \\
S15 & Dinamiza e moderniza processos de trabalho. & 0,350 & 0,436 \\
S51 & Toma providências para sanar dificuldades ao desempenho eficaz. & 0,350 & 0,456 \\
S29 & Desvaloriza os esforços do funcionário. & $-0,345$ & 0,344 \\
S23 & Atualiza o funcionário quanto às novas tecnologias. & 0,338 & 0,476 \\
S04 & O funcionário conhece metas de desempenho esperadas. & 0,327 & 0,217 \\
S18 & Desenvolve as capacidades do funcionário. & 0,319 & 0,312 \\
\hline
\end{tabular}

A segunda escala, denominada de carga de trabalho, refere-se às exigências e à sobrecarga de tarefas atribuídas aos funcionários, devido às altas demandas de produção. Esse fator obteve índice de confiabilidade de 0,80; explica 5,16\% da variância das respostas da amostra, e contém 9 itens. Na Tabela 3, a seguir, observa-se que o item referente à carga de trabalho excessiva foi o que obteve maior carga fatorial, inspirando o nome atribuído ao fator.

A terceira escala, suporte material, refere-se à opinião da amostra sobre a disponibilidade, adequação, suficiência e qualidade dos recursos materiais e financeiros fornecidos pela organização para apoiar a execução eficaz das tarefas. Refere-se também à percepção do trabalhador sobre os esforços organizacionais de modernização e dinamização dos processos de trabalho, bem como sobre os de qualificação da mão-de-obra interna. Esta subescala obteve elevado índice de confiabilidade ( $\alpha$ de Cronbach) de 0,91 . A Tabela 4 apresenta as cargas fatoriais e as comunalidades associadas aos 17 itens componentes do fator 3 . 


\section{Tabela 3: Segundo Fator: Carga de Trabalho}

\begin{tabular}{llcc}
\hline Item & \multicolumn{1}{c}{ Conteúdo básico dos itens } & $\begin{array}{c}\text { Carga } \\
\text { Fatorial }\end{array}$ & h2 \\
\hline S33 & Submete o funcionário a uma carga excessiva de trabalho. & 0,700 & 0,477 \\
S37 & Obriga o funcionário a cumprir horas extras. & 0,671 & 0,414 \\
S45 & Suga a energia do funcionário. & 0,653 & 0,434 \\
S34 & Sobrecarrega de trabalho os melhores funcionários. & 0,578 & 0,424 \\
S43 & Interessa-se apenas pela produção. & 0,443 & 0,489 \\
S50 & Determina prazos irreais para a entrega de trabalhos. & 0,404 & 0,358 \\
S38 & Coloca funcionários em locais incompatíveis com suas características pessoais. & 0,367 & 0,371 \\
S24 & Chama a atenção por pequenos erros. & 0,328 & 0,140 \\
S14 & Desconsidera os interesses pessoais do funcionário, ao tomar decisões & 0,317 & 0,161 \\
& administrativas que o envolvem. & & \\
\hline
\end{tabular}

Tabela 4: Terceiro Fator: Suporte Material

\begin{tabular}{llcc}
\hline Item & \multicolumn{1}{c}{ Conteúdo básico dos itens } & \multicolumn{2}{c}{ Carga } \\
& & hatorial & h2 \\
\hline S28 & Fornece os equipamentos necessários ao desempenho eficaz. & 0,834 & 0,620 \\
S27 & Efetua constantemente a manutenção de máquinas e equipamentos. & 0,731 & 0,478 \\
S52 & Procura adquirir equipamentos modernos de trabalho. & 0,664 & 0,502 \\
S30 & Fornece equipamentos de má qualidade. & $-0,643$ & 0,394 \\
S05 & Fornece materiais em quantidade suficiente. & 0,640 & 0,454 \\
S23 & Atualiza o funcionário quanto às novas tecnologias. & 0,505 & 0,476 \\
S12 & Melhora constantemente as condições físicas dos locais de trabalho. & 0,503 & 0,419 \\
S42 & Mantém sujos os locais de trabalho. & $-0,486$ & 0,305 \\
S32 & Mantém inadequados os ambiente de trabalho. & $-0,476$ & 0,350 \\
S22 & Oferece suporte financeiro extra. & 0,428 & 0,266 \\
S39 & Libera recursos financeiros em tempo hábil. & 0,428 & 0,315 \\
S01 & Deixa faltar os materiais necessários ao bom desempenho. & $-0,421$ & 0,255 \\
S35 & Adquire lentamente os equipamentos de segurança no trabalho. & $-0,370$ & 0,410 \\
S51 & Toma providências para sanar dificuldades ao desempenho eficaz. & 0,362 & 0,456 \\
S15 & Dinamiza e moderniza os processos de trabalho. & 0,361 & 0,436 \\
S47 & Investe na capacitação profissional do funcionário. & 0,334 & 0,354 \\
S43 & Interessa-se apenas pela produção. & $-0,324$ & 0,489 \\
\hline
\end{tabular}

A última escala, denominada práticas organizacionais de ascensão, promoção e salários, apresentada na Tabela 5 , na seqüência, refere-se à opinião da amostra acerca das práticas organizacionais de retribuição financeira, promoções e ascensão funcionais. Nesta tabela observa-se que o item mais relacionado ao fator 4 é o S46. Essa escala, que contém 11 itens, também pode ser considerada confiável, uma vez que obteve alto índice de consistência $(\alpha=0,83)$; explica $3,38 \%$ da variância observada nas respostas da amostra.

Observa-se, nas tabelas de 1 a 5 , que o fator geral e 3 das 4 subescalas são bipolares, indicando que a amostra fez distinções entre os itens de conteúdo desfavorável e favorável. 
Tabela 5: Quarto Fator: Práticas Organizacionais de Ascensão, Promoção e Salários

\begin{tabular}{llcc}
\hline Item & \multicolumn{1}{c}{ Conteúdo básico dos itens } & $\begin{array}{c}\text { Carga } \\
\text { Fatorial }\end{array}$ & h2 \\
& & $-0,654$ & 0,513 \\
S46 & Promoção e ascensão compatíveis com as aspirações pessoais do func. & 0,611 & 0,366 \\
S17 & Oferece raras oportunidades de promoção. & $-0,585$ & 0,357 \\
S09 & Propicia salários compatíveis com os melhores do mercado. & 0,580 & 0,362 \\
S11 & Final de carreira com salários baixos. & $-0,556$ & 0,347 \\
S25 & Promove o funcionário para cargos de melhor remuneração. & $-0,519$ & 0,422 \\
S21 & Salários que reduzem o impacto da inflação. & $-0,494$ & 0,301 \\
S03 & Paga salário digno ao funcionário. & $-0,479$ & 0,392 \\
S08 & Funcionário exemplar recebe mais recompensas que os outros. & 0,428 & 0,228 \\
S44 & Não incentiva escolaridade excedente. & 0,403 & 0,252 \\
S48 & Mantém baixas as recompensas financeiras. & 0,374 & 0,275 \\
S36 & Não oferece cargos importantes aos funcionários. & & \\
\hline
\end{tabular}

\section{Consideraçóes Finais e Recomendaçóes}

Do mesmo modo que Eisenberger et al. (1986), no presente trabalho encontraram-se evidências empíricas de que o construto percepção de suporte organizacional é essencialmente unidimensional. Esses resultados sugerem que o trabalhador formula opiniões globais sobre o quanto a organização valoriza suas contribuições e cuida do seu bem-estar. Essas opiniões referem-se às crenças do trabalhador sobre o comportamento da organização como um todo e não sobre o comportamento de agentes organizacionais específicos como os de chefes e líderes.

Os resultados, no entanto, também mostraram que o fator geral contém 4 escalas correlacionadas entre si, mas igualmente confiáveis e teoricamente válidas, o que possibilita ao pesquisador identificar com maior precisão os principais componentes do construto percepção de suporte organizacional.

O conceito de suporte organizacional, como utilizado neste estudo, não se confunde com os de clima, cultura e qualidade de vida no trabalho e possibilita análises mais precisas do seu relacionamento com outros conceitos e variáveis de comportamento organizacional.

Tanto o fator geral como os subfatores podem ser úteis na produção de conhecimento científico e na realização de diagnósticos organizacionais. A escolha do instrumento de coleta de dados dependerá do contexto e dos objetivos do estudo. Profissionais da área de recursos humanos, por exemplo, podem utilizar os itens componentes do fator geral como instrumentos de diagnóstico de problemas 
organizacionais específicos. Em casos similares a esse, onde a investigação tem caráter exploratório e analítico, o uso do fator único de suporte parece ser o mais indicado, pois subsidia decisões gerenciais mais pontuais e eficazes. As subescalas, por outro lado, podem ser utilizadas individualmente para examinar as relações entre os componentes de suporte e outras variáveis de comportamento organizacional, como desempenho, comprometimento, cidadania. Além disso, essas escalas também podem ser usadas para analisar com maior profundidade os relacionamentos entre os próprios conceitos que as compõem.

Mais pesquisas são necessárias para garantir maior generalidade aos resultados obtidos no presente trabalho. O questionário Percepção de Suporte Organizacional deve ser aplicado em outras amostras de trabalhadores e organizações brasileiras, com a finalidade de examinar a estabilidade da estrutura empírica do conceito. Além disso, devem ser realizadas pesquisas sobre o relacionamento entre percepção de suporte e efetividade organizacional, aplicando-se o questionário em organizações produtivas, eficazes e bem sucedidas e em organizações ineficazes e ineficientes, a fim de aferir o poder diagnóstico do fator geral e das subescalas.

No nível de variáveis individuais, devem ser realizadas pesquisas para examinar o relacionamento entre restrições situacionais ao desempenho e níveis de desempenho individual de modo que se teste a hipótese de Peters e O'Connor (1982) de que a falta de suporte organizacional exerce influência diferencial sobre os indivíduos, dependendo do seu nível de competência. Para esses autores, as restrições ambientais afetariam mais o desempenho do funcionário exemplar do que medíocre.

Os pesquisadores da área de organizações podem, também, ampliar a generalização dos resultados das investigações brasileiras realizadas por Dias (1993), Bastos (1994), Borges-Andrade (1994a, 1994b) e Dias e Moraes (1994) sobre o relacionamento entre comprometimento organizacional e variáveis relativas à organização. Além desses, devem ser desenvolvidos trabalhos que examinem as relações entre variáveis de percepção de suporte, criatividade e cidadania organizacional em amostras de trabalhadores e organizações nacionais, visando a aumentar a abrangência dos resultados de Eisenberger, Fasolo e LaMastro (1990) e Siqueira (1995).

O questionário Percepção de Suporte Organizacional, além de facilitar a produção de conhecimentos científicos na área de comportamento organizacional, poderá vir a ser útil como instrumento de diagnóstico e avaliação organizacionais e também como indicador indireto de necessidades de treinamento gerencial nas áreas de gestão de desempenho e práticas de valorização do funcionário. Além dessas aplicações, parte do referido questionário foi aplicado, juntamente com 
itens de suporte à transferência de treinamento, em estudos sobre impacto do treinamento no trabalho realizados por Britto (1999) e Oliveira-Castro (1999), a fim de investigar de que modo as opiniões do trabalhador sobre suporte estão relacionadas com três níveis de avaliação de treinamento: reações, aprendizagem e impacto no cargo.

\section{NOTAS}

${ }^{1}$ Este projeto foi financiado pelo CNPq.

\section{ReFERÉNCIAS BibLIOGRÁfiCAS}

\section{BASTOS, A.V. B.}

Comprometimento organizacional: seus antecedentes em distintos setores da administração e grupos ocupacionais. Temas em Psicologia, n. 1, p. 73-90, 1994.

BORGES-ANDRADE, J. E.

Comprometimento organizacional na administração pública e em seus segmentos meio e fim. Temas em Psicologia, n. 1, p. 49-61, 1994a.

Conceituação e mensuração de comprometimento organizacional. Temas em Psicologia, n. 1, p. 3747, 1994b.

BRITTO, M. J. P.

Avaliação de impacto de treinamento na área de reabilitação : preditores individuais e situacionais. Brasília, 1999. Dis- sertação (Mestrado) - Universidade de Brasília.

COOK, J. D. et al.

The experience of work : a compendium and review of 249 measures and their use. London : Academic Press, 1981.

DIAS, J. M. G.

Preditores do comprometimento organizacional : um estudo de caso na EMATER - MG. Belo Horizonte, 1993. Dissertação (Mestrado) - Universidade Federal de Minas Gerais.

DIAS, J. M. G.;

MORAES, L. F. R.

Preditores de comprometimento organizacional na EMATER MG. Temas em Psicologia, n. 1, p. 91-102, 1994. 
EISENBERGER, R. et al.

Perceived organizational support. Journal of Applied Psychhology, v. 72, n. 3, p. 500-507, 1986.

EISENBERGER, R.;

FASOLO, P.;

LAMASTRO, V. D.

Perceived organizational support and employee diligence, commitment and innovation. Journal of Applied Psychology, v. 75, n. 1, p. 51-59, 1990.

GAVIN, J. F.;

MAYNARD, W. S.

Perceptions of corporate social responsability. Personnel Psychology, v. 28, n. 3, p. 189206, 1975.

GOULDNER, A.W.

The norm of reciprocity : a preliminary statement. American Social Review, v. 25, n. 2, p. 161178, 1960.

MOWDAY, R. T.;

SUTTON, R. I.

Organizational behavior : linking individuals and groups to organizational contexts. Annual Review of Psychology, v. 44, p. 195-229, 1993.

OLIVEIRA-CASTRO, G. A.

Um modelo integrado de avaliação do impacto do treinamen- to no trabalho - IMPACT. Brasília, 1999. Tese (Doutorado em Psicologia) - Instituto de Psicologia, Universidade de Brasília.

PETERS, L. H.;

O'CONNOR, E. J.

Situational constraints and work outcomes : the influence of frequently overlooked construct. Academy of Management Review, v. 5, n. 3, p. 391-397, 1982.

PUENTE, K. P.;

GÜNTHER, H.

Tradução e validação da escala de clima social do local de trabalho de Moos. In: XXVI CONGRESSO INTERAMERICANO DE PSICOLOGIA (1997 : São Paulo). Anais... São Paulo : Sociedade Interamericana de Psicologia, 1997. p. 52. resumo.

QUIRINO, T. R.;

XAVIER, O. S.

Qualidade de vida no trabalho de organizações de pesquisa. Revista de Administração, v. 22, n. 1, p. 21-82, 1987.

SBRAGLIA, R.

Um estudo empírico sobre o clima organizacional em instituições de pesquisa. Revista de Pesquisa em Organização, v. 18, n. 2, p. 30-39, 1983. 
SHORE, L. M.;

TETRICK, L. E.

A construct validity study of survey of perceived organizational support. Journal of Applied Psychology, v. 76, n. 5, p. 637643, 1991.

SIQUEIRA, M. M. M.

Antecedentes do comportamento de cidadania organizacional : a análise de um modelo póscognitivo. Brasília, 1995. Tese (Doutorado) - Universidade de Brasília.
SOUZA, E. L. P.

Clima e estrutura de trabalho. Revista de Administração, v. 18, n. 3, p. 68-71, 1983.

XAVIER, O. S.

A cultura de organizações de pesquisa : percepção e aspirações. Revista de Administração, v. 22, n. 2, p. 03-16, 1987.

ZOHAR, D.

Safety climate in industrial organizations : theoretical and applied implications. Journal of Applied Psychology, v. 65, n. 1, p. 96-102, 1980. 